\title{
Lifetime prediction of nitrile rubber under compression stress in transformer oil
}

\author{
Yi-hua Qian ${ }^{1, a}$, Hong-zhao Xiao ${ }^{2, b}$, Ming-hao Nie ${ }^{2, c}$, Yao-hong Zhao ${ }^{1, d}$, Yun-bai \\ Luo $^{2, e}$, Shu-ling Gong ${ }^{2, f}$ \\ ${ }^{1}$ Electric Power Research Institute of Guangdong Power Grid Corporation, Guangzhou, \\ Guangdong, China \\ ${ }^{2}$ College of Chemistry and Molecular Sciences, Wuhan University, Wuhan, Hubei, China \\ aemail: 13926035192@163.com, bemail: 171845955@qq.com, cemail: 1004571616@qq.com, \\ demail:kennyaoo@126.com, eemail:ybai@whu.edu.cn, ${ }^{\mathrm{f}}$ email:gongsl@whu.edu.cn
}

Keywords: nitrile rubber; aging; lifetime prediction; compression stress; oil.

Abstract: The aging tests of nitrile rubber were carried on in transformer oil, and under compression in transformer oil. The effects of compression stress on the thermal aging behaviors of nitrile rubber were studied by mechanical property measurements. The variations of physical properties during the ageing process were analyzed and compared. The change in elongation at break aging under compression stress in oil was lower than that aging in oil. The lifetime of NBR at $25^{\circ} \mathrm{C}$ was predicted and compared with the compression set or elongation at break as evaluation indexes, and $50 \%$ as critical value.

\section{Introduction}

Nitrile rubber (NBR) is often used in sealing applications, particularly in oil and gas distribution, due to its good oil resistance and low gas permeability. However, nitrile rubber is relatively sensitive to aging. ${ }^{[1-3]}$

Much work has been done to study the aging behavior as well as the aging mechanism at elevated temperature ${ }^{[4-12]}$, UV light ${ }^{[13]}$ and Ozone. ${ }^{[14]}$. The accelerating effect of applied mechanical loading on aging has also been observed. ${ }^{[15-17]}$ Xiong et al. ${ }^{[15]}$ studied the aging behavior of sulfured nitrile-butadiene rubber under the bending and tensile-bending stress, and calculated the storage life of NBR according to Arrhenius equation by the criterion of elongation.

Many authors have also presented studies describing the ageing behavior of nitrile rubbers in chemical environments. ${ }^{[18-21]}$ Buckley et al. ${ }^{[21]}$ studied the influence of liquid media on lifetime predictions of nitrile rubber and it was determined that the activation energy for oxidative degradation of a particular NBR O-ring had a value, $82 \mathrm{~kJ} / \mathrm{mol}$, that was invariant to the immersion liquid.

However, NBR components experience complex mechanical loads in aggressive chemical environments in real applications, such as gaskets in transformer. It is well worth studying the effect of aggressive medium and applied load simultaneously on the properties of NBR. And little work concerns the comparison of prediction lifetime by using fracture strain and compression set as the indexes of the material's performance. In this paper, the effect of compression stress on the thermal aging behaviors of NBR for oil seal and prediction lifetime were studied.

\section{Experimental}

Materials. Vulcanized NBR in sheet form with a thickness of $2 \mathrm{~mm}$ and cylindrical specimens with $12.5 \mathrm{~mm}$ thickness and $29 \mathrm{~mm}$ diameter were supplied by Hangzhou Dongqing Rubber Company Limited, China. The sheet was punched into dumb-bell specimens according to ISO 37-2011. SINOPEC 25 transformer oil was supplied by China Petroleum \& Chemical Corporation, China.

Accelerated ageing tests. Thermooxidative aging tests were carried out in a convection oven. The NBR specimens were placed between stainless steel plates that were screwed together to compressing the samples to a constant deflection (25\%), and then immersed fully in the SINOPEC 25 transformer oil contained in a covered vessel. For comparison, another specimen, in a free state without 
compression, were also immersed in the oil bath in the oven for aging. The aging temperature was chosen as $70^{\circ} \mathrm{C}, 90^{\circ} \mathrm{C}, 110^{\circ} \mathrm{C}$.

Mechanical properties. The tensile test was carried out with a AGS-X series electronic tensile testing machine (SHIMADZU Co., Ltd., Japan). Dumbbell shaped specimens were tested at a cross-head speed of $500 \mathrm{~mm} / \mathrm{min}$ at room temperature following the requirement of ISO 37-2011.

The cylindrical shaped samples with $12.5 \mathrm{~mm}$ thickness and $29 \mathrm{~mm}$ diameter with smooth and uniform surface were used to measure the indentation hardness and compressions set of the samples. Hardness indentations were made in the various positions. Ten readings were taken from different areas of the testing samples and the average value was estimated. The compression set (CS) was determined according to ISO 815 by compressing the cylindrical samples to a constant deflection $(25 \%)$. Three samples were measured for hardness and compression sets.

\section{Results and Discussion}

Effect of compression stress and oil on the aging of NBR. Hardness, elongation at break and compression set are key mechanical properties for NBR rubbers. The mechanical properties of aged NBR samples at $70^{\circ} \mathrm{C}$ with testing time under different conditions were measured. During thermal aging, under different conditions, elongation at break decreased with time, while hardness and compression set increased. But the changes were different, as shown in Fig.1, Fig. 2, and Fig. 3.

Fig. 1 showed the hardness change of NBR aged at $70^{\circ} \mathrm{C}$ under different conditions with the aging time. The curves of hardness in oil and under compression in oil had the similar trend. Hardness decreased rapidly in the initial aging (0-5 days) due to the oil swelling, after reaching the swelling equilibrium, the hardness of rubber increased gradually with aging time. But the hardness of aged in oil was smaller than that of under compression in oil. Compressive stress reduced the hardness of rubber and at the same time reduced the absorption of oil, so aged under compression in oil, the hardness decreased slowly.

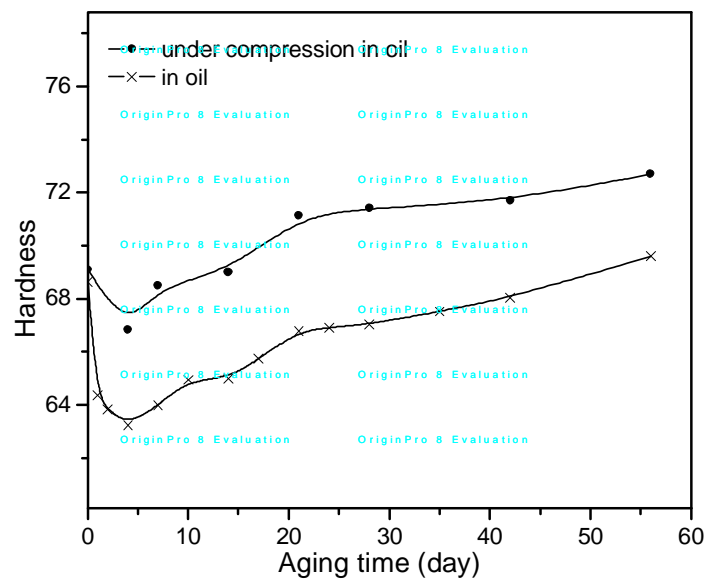

Fig.1. Hardness versus aging time of NBR aged at $70^{\circ} \mathrm{C}$ under various aging conditions

Fig. 2 showed the elongation at break change of NBR aged at $70^{\circ} \mathrm{C}$ under different conditions with aging time. When NBR soaked in transformer oil, in a certain extent, prevented air into the rubber which inhibited the rubber thermal oxidative aging chain scission reactions, crosslinking was dominant, so the elongation at break in oil condition was generally decreased in the early aging period. After 42-day aging, too much cross-linking led the elongation at break decreased dramatically.

The elongation at break of NBR aged under compression was also smaller than that aged in absence of compression at the same oil environment. The applied compressive stress made the molecular chain orientation, constrained the relaxation behavior of NBR, and increased chain scission reactions. So in 
the whole aging stage, the elongation at break under compression condition was lower than that in the condition of no compression.

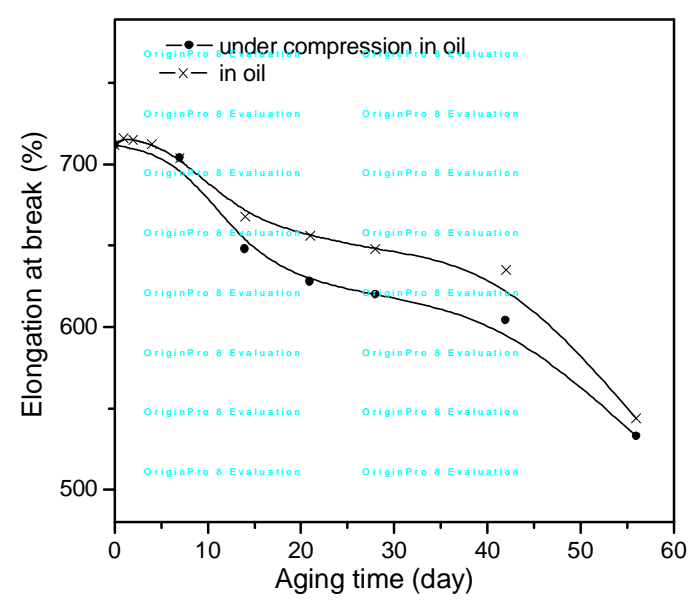

Fig. 2. Elongation at break versus aging time of $\mathrm{NBR}$ aged at $70^{\circ} \mathrm{C}$ under various aging conditions

Fig. 3 showed the compression set change of NBR aged at $70^{\circ} \mathrm{C}$ under compression in oil with the aging time. In the initial aging (0-10 days) compression set increased rapidly (by about 25\%), then gradually and slowly increased with heating time.

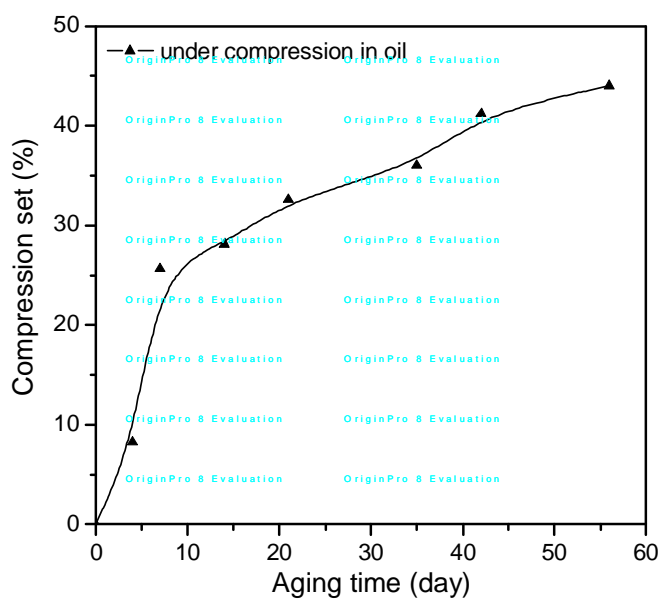

Fig. 3. Compression set versus aging time of NBR aged at $70^{\circ} \mathrm{C}$

Lifetime prediction. Elongation at break $(\varepsilon)$ and compression set (CS) are always chosen as the failure property for lifetime predictions, as both chain scission and crosslinking reactions add up to decrease elongation at break and increase CS. The aging tests of nitrile rubber were conducted systematically at $70^{\circ} \mathrm{C}, 90^{\circ} \mathrm{C}, 110^{\circ} \mathrm{C}$ under two conditions. Fig.4 and Fig.5 showed the change of compression set and elongation at break with aging time. In all cases, compression set increased and elongation at break decreased with time of exposure, and with increasing temperature. 

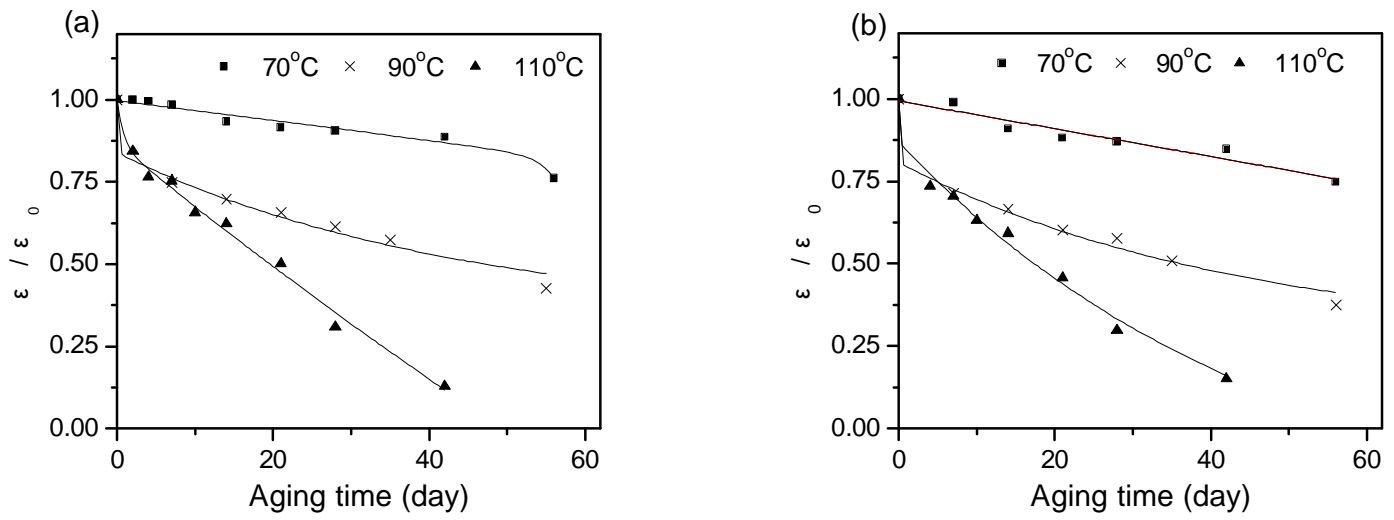

Fig. 4. Change of the elongation at break: (a) in oil; (b) under compression in oil; $\varepsilon, \varepsilon_{0}$ is elongation at break after aging and before aging.

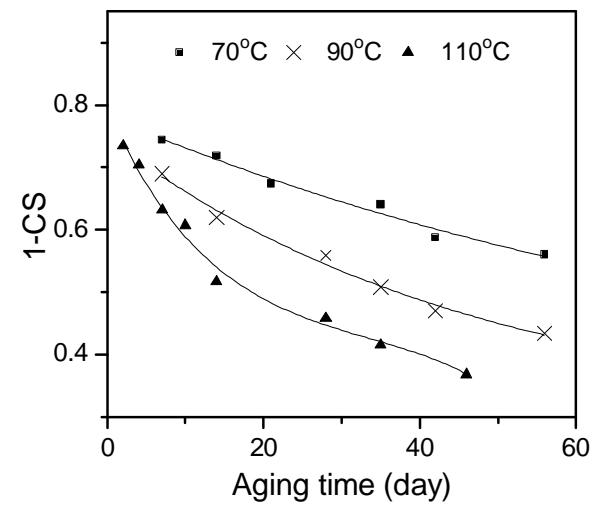

Fig. 5. Change of the compression set under compression in oil.

The lifetime of NBR can be predicted by using the Arrhenius life prediction method. When appropriate, this method predicts a liner relation between the logarithm of time $(t)$ to a specified amount of material property change (e.g. 50\% in our work), and the reciprocal of the absolute temperature $(T)$. The plot of $\ln t$ versus $1 / T$ was fitted by the linear equation as shown in Fig. 6 and Fig.7.
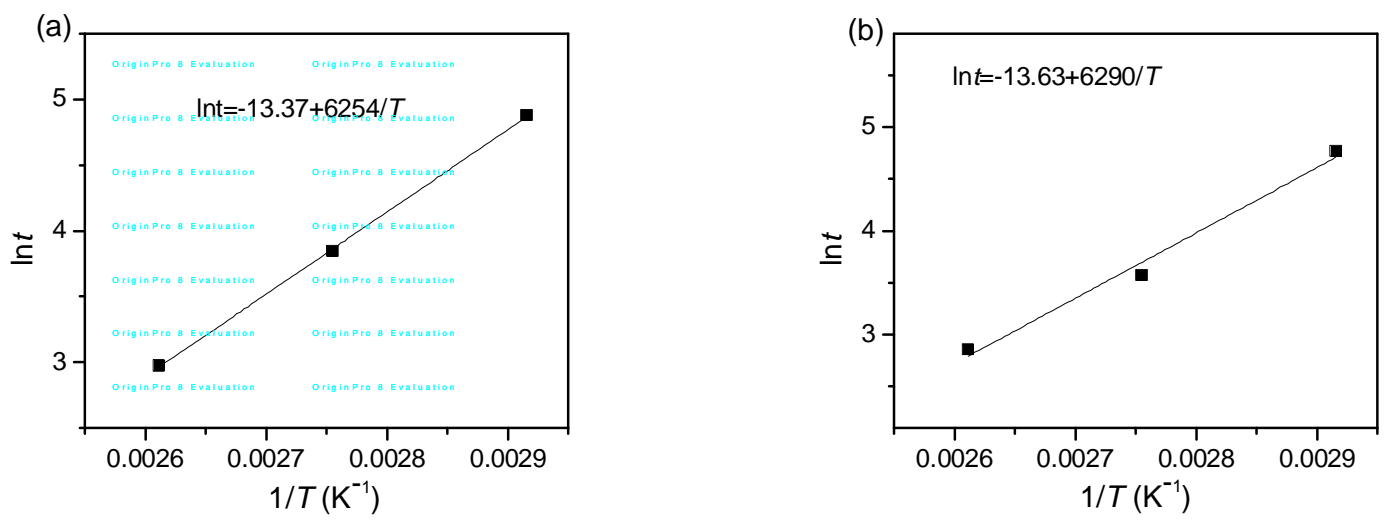

Fig. 6. Arrhenius plots for elongation at break: (a) in oil; (b) under compression in oil. 


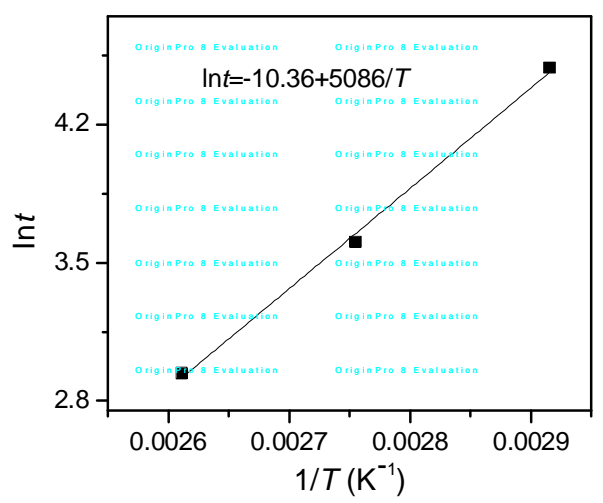

Fig. 7. Arrhenius plots for compression set under compression in oil.

The activation energy was obtained by multiplying the slope of the fitting line by $\mathrm{R}$, the gas constant. The lifetime at $25^{\circ} \mathrm{C}$ was estimated by extrapolation of the fitting line. For the elongation at break as evaluation index, the activation energy was $\sim 52.0 \mathrm{~kJ} / \mathrm{mol}$, and $\sim 52.3 \mathrm{~kJ} / \mathrm{mol}$, respectively; while the lifetime was 2037 and 1766 days, respectively for NBR aged in oil, and under compression in oil. The lifetime of NBR aged in oil was longer than that under compression in oil. So compression stress accelerated the aging of NBR.

For compression set as evaluation index, the activation energy was calculated to be $\sim 39.7 \mathrm{~kJ} / \mathrm{mol}$. The lifetime at $25^{\circ} \mathrm{C}$ was 814 days. The lifetimes using CS as evaluation index were much shorter than those for elongation.

\section{Conclusions}

The prediction lifetime using different evaluation index was different greatly. For the life prediction of NBR, the lifetime at $25^{\circ} \mathrm{C}$ was 814 days by using compression set in transformer oil as evaluation index.

\section{Acknowledgments}

This work was supported by project of China Southern Power Grid Corporation (K-GD2014-183) and Wuhan University Experiment Technology Project Funding.

\section{References}

[1] N. Grassie, A. Heaney: Rubber Chem. Technol. Vol. 48(1975), p.678.

[2] R. N. Datta, N. M. Huntink, S. Datta, A. G. Talma: Rubber Chem. Technol. Vol. 80(2007), p.436.

[3] J. A. Kuczkowski: Rubber Chem. Technol. Vol. 84(2011), p. 273.

[4] P. R. Morrell, M. Patel, A. R. Skinner: Polym. Test. Vol. 22(2003), p. 651.

[5] M. Hakkarainen, A. C. Albertsson, S. Karlsson: Int. J. Polym. Anal. Charact. Vol. 8(2003), p. 279.

[6] T. Kawashima, T. Ogawa: Anal. Sci. Vol. 21(2005), p. 1475.

[7] C. S. Woo, S. S. Choi, Member IEEE, S. B. Li, S. H.Kim: IEEE T. Reliab. Vol. 59(2010), p.11.

[8] S. S. Choi, C. J. Kim: J. Ind. Eng. Chem. Vol. 18(2012), p. 1166.

[9] E. V. Bystritskaya, T. V. Monakhova, V. B. Ivanov: Polym. Test. Vol. 32(2013), p. 197.

[10] J. H. Zhao, R. Yang, R. Iervolino, S. J. Barbera: Appl. Polym. Sci. Vol. 132(2015), p. 41319. 
[11] X. Liu, J. H. Zhao, R. Yang, R. Iervolino, S. Barbera: Polym. Degrad. Stab. Vol. 128(2016), p. 99.

[12] Z. M. Zhu, Q. Cheng, C. K. Jiang, J. W. Zhang, H. Jiang: Wear. Vol. 352-353(2016), p. 155.

[13] H. Zhang, C. Chang: Adv. Mater. Res. Vol. 1082(2015), p. 42.

[14] T. Hara, T. Ogawa, S. OSawa, S. Nakamura, S. Yoshida, K. Minegishi: J. Materials life Soc. Vol. 10(1998), p. 93.

[15] Y. Xiong, B. Q. Fu, S. Y. Guo, Z. Lu: Equip. Environ. Eng. Vol. 9(2012), p. 52.

[16] P. Budrugeac: Polym. Degrad. Stab. Vol. 47(1995), p. 129.

[17] Z. M. Zhu, C. K. Jiang, Q. Cheng, J. W. Zhang, S. Y. Guo, Y. Xiong, B. Q. Fu, W. L. Yang, H. Jiang: RSC Adv. Vol. 5(2015), p. 90178.

[18] W. Trakarnpruk, S. Porntangjitlikit: Renew. Energy Vol. 33(2008), p. 1558.

[19] B. Alcock, J. K. Jørgensen: Polym. Test. Vol. 46(2015), p. 50.

[20] X. R. Lv, H. M. Wang, S. J. Wang: Wear. Vol. 328-329(2015), p. 414.

[21] G. S. Buckley, M. Roland: J. Appl. Polym. Sci. Vol.131(2014), p.40296 